\title{
General health checks in adults for reducing morbidity and mortality from disease: Cochrane systematic review and meta-analysis
}

\author{
Lasse T Krogsbøll doctor, Karsten Juhl Jørgensen doctor, Christian Grønhøj Larsen doctor, Peter \\ C Gøtzsche professor, director
}

Nordic Cochrane Centre, Rigshospitalet, Blegdamsvej 9, 2100 Copenhagen, Denmark

\begin{abstract}
Objectives To quantify the benefits and harms of general health checks in adults with an emphasis on patient-relevant outcomes such as morbidity and mortality rather than on surrogate outcomes.

Design Cochrane systematic review and meta-analysis of randomised trials. For mortality, we analysed the results with random effects meta-analysis, and for other outcomes we did a qualitative synthesis as meta-analysis was not feasible.

Data sources Medline, EMBASE, Healthstar, Cochrane Library, Cochrane Central Register of Controlled Trials, CINAHL, EPOC register, ClinicalTrials.gov, and WHO ICTRP, supplemented by manual searches of reference lists of included studies, citation tracking (Web of Knowledge), and contacts with trialists.

Selection criteria Randomised trials comparing health checks with no health checks in adult populations unselected for disease or risk factors. Health checks defined as screening general populations for more than one disease or risk factor in more than one organ system. We did not include geriatric trials.
\end{abstract}

Data extraction Two observers independently assessed eligibility, extracted data, and assessed the risk of bias. We contacted authors for additional outcomes or trial details when necessary.

Results We identified 16 trials, 14 of which had available outcome data (182 880 participants). Nine trials provided data on total mortality (11 940 deaths), and they gave a risk ratio of 0.99 (95\% confidence interval 0.95 to 1.03). Eight trials provided data on cardiovascular mortality (4567 deaths), risk ratio 1.03 (0.91 to 1.17), and eight on cancer mortality (3663 deaths), risk ratio 1.01 (0.92 to 1.12). Subgroup and sensitivity analyses did not alter these findings. We did not find beneficial effects of general health checks on morbidity, hospitalisation, disability, worry, additional physician visits, or absence from work, but not all trials reported on these outcomes. One trial found that health checks led to a $20 \%$ increase in the total number of new diagnoses per participant over six years compared with the control group and an increased number of people with self reported chronic conditions, and one trial found an increased prevalence of hypertension and hypercholesterolaemia. Two out of four trials found an increased use of antihypertensives. Two out of four trials found small beneficial effects on self reported health, which could be due to bias.

Conclusions General health checks did not reduce morbidity or mortality, neither overall nor for cardiovascular or cancer causes, although they increased the number of new diagnoses. Important harmful outcomes were often not studied or reported.

Systematic review registration Cochrane Library, doi:10.1002/ 14651858.CD009009.

\section{Introduction}

General health checks have long been common elements of healthcare in some countries such as the United States. ${ }^{12}$ In the UK, the publicly funded NHS Health Check programme was introduced in 2009, and in Denmark an organised health check programme for the general public has been suggested, but now seems abandoned. Health checks are also performed by some primary care physicians outside organised programmes and by commercial clinics. ${ }^{3}$ However, evidence for their effectiveness has been lacking.

General health checks involve a contact between a person and a healthcare professional to identify signs, symptoms, or risk factors for disease that were previously unrecognised. They are combinations of screening tests, few of which have been adequately studied in randomised trials. For example, although the benefits and harms of treatments for conditions such as hypertension and diabetes have been extensively studied in randomised trials, screening asymptomatic people for these conditions has not. ${ }^{45}$ 
Health checks are intended to reduce morbidity and prolong life. Theoretically, there are many possible benefits of general health checks, through apparently intuitive mechanisms. The detection of elevated risk factors such as hypertension or hypercholesterolaemia may lead to reductions in morbidity and mortality through preventive treatment. Some tests may detect precursors to disease, such as cervical dysplasia, the treatment of which may prevent cancer from developing. Also, it may be beneficial to detect signs or symptoms of manifest disease that the person had not deemed important. Some people might improve their lifestyle because of the test results and counselling, and healthy people may feel reassured.

While we cannot be certain that general health checks lead to benefit, we know that all medical interventions can lead to harm. Possible harms from health checks are overdiagnosis, overtreatment, distress or injury from invasive follow-up tests, distress due to false positive test results, false reassurance due to false negative test results, possible continuation of adverse health behaviours due to negative test results, adverse psychosocial effects due to labelling, and difficulties with getting insurance. Last but not least, organised programmes of general health checks are likely to be expensive and may result in lost opportunities to improve other areas of healthcare.

Existing reviews on this topic have had narrow definitions of the intervention, included relatively few trials with clinical outcomes, and did not document effects on morbidity or mortality. ${ }^{6-8}$

We aimed to investigate the balance between benefits and harms of general health checks in adult populations, unselected for diseases or risk factors, and performed by any type of healthcare provider. We did not focus on surrogate outcomes because they may be seriously misleading ${ }^{9}$ and do not capture harmful effects. ${ }^{10}$ There is also a risk of biased loss to follow-up in non-blinded trials, whereas mortality status can usually be obtained for all randomised people.

\section{Methods}

The review was done according to a detailed, peer reviewed protocol, which is available in the Cochrane Library.

\section{Selection criteria}

We included randomised trials of general health checks compared with no health checks. The participants had to be 18 years or older and unselected for specific known risk factors or diseases, such as hypertension or heart disease. The setting had to be primary care or the community (that is, we did not include trials in patients recruited from hospital clinics). We accepted trials regardless of the type of provider of the health check and regardless of where the health check was performed (such as general practice or a special clinic).

We defined general health checks as screening for more than one disease or risk factor in more than one organ system, whether performed only once or repeatedly. This definition excludes trials of screening for single diseases in isolation, such as prostate cancer, and trials of single screening tests that may detect more than one disease, such as spirometry. We accepted trials which included a lifestyle intervention (such as advice on diet, smoking, and exercise) in addition to screening, since this is a fairly well defined intervention often incorporated into health checks.

Although we originally planned to include trials of geriatric screening, we found that they included many interventions in addition to screening, such as falls prevention and specialist medication review. Thus, we excluded trials described as specifically targeting older people only, or which only enrolled people aged $>65$.

\section{Search methods for identification of studies}

Studies were identified using the Cochrane Central Register of Controlled Trials (CENTRAL) 2010, issue 11; Medline (via OVID) (1948 to "In-Process"); EMBASE (via OVID) (1947 onwards); Cumulative Index to Nursing and Allied Health Literature (CINAHL); EbscoHost (1980 onwards); Healthstar (via OVID) (1966 to 2010); and the EPOC Specialised Register. Related systematic reviews were identified by searching the Database of Abstracts of Reviews of Effectiveness (DARE), and ongoing trials were identified by searching ClinicalTrials.gov and WHO ICTRP. The searches were conducted in November and December 2010 and updated in July 2012. An example of a search strategy is available in appendix 1 on bmj.com.

Two observers searched the reference lists of included articles, and one author used citation tracking (Web of Knowledge) on all articles describing eligible trials. We asked authors of the included studies if they were aware of any other published, unpublished, or ongoing studies that could meet our inclusion criteria.

\section{Selection of studies}

Two observers (LTK and CGL or KJJ) independently assessed the potential relevance of all titles and abstracts identified through the searches. Full text copies of potentially relevant articles were assessed for eligibility independently by two authors (LTK and CGL or KJJ). Disagreements were resolved through discussion, involving the other authors (KJJ and PCG) when necessary.

Two authors (LTK and KJJ) independently extracted pre-specified data items from the included articles in a non-blinded fashion and entered them into a pilot tested data extraction form. When our preferred data formats were not available, we extracted what was possible, including narrative accounts if numbers were missing. We preferentially extracted data allowing an intention to treat analysis. We attempted to contact authors when necessary and succeeded in 10 cases.

Two authors (LTK and KJJ) independently assessed risk of bias in the included trials using the Cochrane Risk of Bias tool. The domains formally assessed were sequence generation, allocation concealment, blinding of participants and personnel, blinding of outcome assessment, incomplete outcome data, selective reporting, and other biases. Baseline balance and risk of contamination was also assessed.

\section{Analysis}

Our primary outcomes were total mortality and disease-specific mortality. Our secondary outcomes were morbidity (such as myocardial infarction), number of new diagnoses (total and condition-specific), admission to hospital, disability, patient worry, self reported health, number of referrals to specialists, number of non-scheduled visits to general practitioners, number of additional diagnostic procedures due to positive screening tests, new medications prescribed, frequency and type of surgery, and absence from work.

When cardiovascular and cancer mortality were reported as such, we used those numbers. When they were reported in several disease categories or organ systems, two of us independently combined them into an overall measure of 
cardiovascular or cancer mortality. For example, in one trial we added fatal coronary heart disease and fatal stroke to give a measure of cardiovascular mortality.

Meta-analysis was feasible only for our primary outcomes. We calculated risk ratios with $95 \%$ confidence intervals using the random effects model. To allow incorporation of adjusted effect estimates we used the generic inverse variance approach. Heterogeneity was investigated with the $\mathrm{I}^{2}$ statistic.

We conducted the following pre-specified subgroup analyses: one versus multiple health checks, lifestyle intervention versus no lifestyle intervention, length of follow-up ( $\leq 5$ years versus $>5$ years), trial age (started before 1980 versus after 1980), geographical location (Europe versus US), examination by a physician, and risk of bias (selection bias, performance bias, detection bias, attrition bias, contamination). We did one pre-specified sensitivity analysis, excluding cluster randomised trials, and one post hoc sensitivity analysis excluding trials judged to be biased towards no effect. The results of these are presented in the corresponding Cochrane review. ${ }^{11}$ For other outcomes, we summarised the results in tables and did a qualitative synthesis.

\section{Results}

\section{Results of the search}

We identified 16 eligible trials, but two of these never published results. ${ }^{12} 13$ Thus, we analysed 14 trials, of which nine had data on mortality (fig $1 \Downarrow$ ).

\section{Study characteristics}

The 14 trials analysed included a total of 182880 participants, with 76403 allocated to health checks and 106477 to control groups. The length of follow-up varied from 1 to 22 years (table $1 \Downarrow)$. The participants were recruited from general practice in five trials, ${ }^{14-18}$ the general population in seven trials, ${ }^{19-25}$ health plan members in one trial, ${ }^{26}$ and the workplace in one trial. ${ }^{27}$ The health checks took place in general practice in four trials, a screening clinic in five trials, at the workplace in one trial, in a hospital in one trial, and in three trials it was not clear. Table $2 \Downarrow$ provides a summary of the trials' methods, and table $3 \Downarrow$ provides an overview of the screening tests used.

\section{Risk of bias in included studies}

Risk of bias varied between trials, and within trials for different outcomes (fig $2 \Downarrow$ ). Most trials randomised participants before any contact was made, effectively leading to concealed allocation. When the randomisation sequence was predictable but likely to provide balanced groups given allocation before contact (such as date of birth), we judged the risk of selection bias to be low. ${ }^{15} 192026$ Of the nine trials that reported mortality, ${ }^{14} 1618-222627$ seven had a low risk of selection bias, and eight had a low risk of attrition bias for that particular outcome. All nine trials reporting mortality could be analysed by intention to treat. By design, three trials were biased towards no effect. ${ }^{14} 1826$ In two of these, the control group was offered health checks before follow-up for mortality ended. In one, the control group had free access to the same health check as the intervention group and, though not actively encouraged, used this option to a considerable extent. In four trials, the follow-up and treatment of detected abnormalities were possibly better in the intervention group than in the control group (for example, follow-up by specialists who used treatment algorithms). ${ }^{19} 2022$ This might have caused bias in favour of screening.
For our secondary outcomes, lack of blinding and missing outcome data were major issues. Funnel plots did not show asymmetry, but the number of trials is low (figs 3-5 $\Downarrow \Downarrow \Downarrow$ ).

\section{Effects of interventions Total mortality}

Nine trials reported on total mortality, and our meta-analysis included 155899 people and 11940 deaths. The median length of follow-up was nine years (range 4-22 years), and the median event rate in the control groups was $7 \%$ (range $2 \%-16 \%$ ). We did not find an effect of general health checks on total mortality, risk ratio 0.99 (95\% confidence interval 0.95 to 1.03 ) (fig $6 \Downarrow$ ). There was no heterogeneity $\left(\mathrm{I}^{2}=0 \%\right)$. Subgroup and sensitivity analyses did not alter this result.

\section{Cause-specific mortality}

For cardiovascular mortality ( 8 trials, 152435 people, 4567 deaths), the median length of follow-up was 10.4 years and the median event rate in the control groups was $3.7 \%$. The pooled estimate was risk ratio 1.03 (0.91 to 1.17$)$, but with large heterogeneity $\left(\mathrm{I}^{2}=64 \%\right.$ ) (fig $\left.7 \Downarrow\right)$. Subgroup and sensitivity analyses did not alter the results, nor explain the heterogeneity. One possible explanation for the heterogeneity is the varying definitions of the outcome among trials. One trial found a large beneficial effect, ${ }^{20}$ and one found a large harmful effect. ${ }^{14}$

For cancer mortality ( 8 trials, 139 290people, 3663 deaths), the median length of follow-up was 10.4 years, and the median event rate in the control groups was $2.4 \%$. The pooled estimate was risk ratio 1.01 ( 0.92 to 1.12$)$ with moderate heterogeneity $\left(\mathrm{I}^{2}=33 \%\right.$ ) (fig $\left.8 \Downarrow\right)$. A high quality trial found a reduction in cancer mortality (risk ratio $0.87(0.76$ to 0.99$)$ ). ${ }^{22}$ That trial did not use cancer screening tests, and was not successful in reducing smoking.

\section{Subgroup and sensitivity analyses}

The pre-specified subgroup analyses resulted in groups with few trials, and the results should be viewed with caution. We did not find any convincing patterns or explanations for the heterogeneity observed.

For cancer mortality, three trials that used only one health check showed a trend towards harm (relative risk 1.10 (1.00 to 1.21)), and five trials that used more than one health check showed a trend towards benefit (relative risk $0.92(0.83$ to 1.02$)$ ). The test for subgroup differences was significant $(\mathrm{P}=0.01)$.

For cardiovascular mortality, the reverse pattern was present. The three trials using only one health check showed a trend towards benefit (relative risk 0.89 (0.69 to 1.14)), and the five trials using more than one health check showed a trend towards harm (relative risk 1.11 ( 0.95 to 1.30$)$ ). The test for subgroup differences was not significant $(\mathrm{P}=0.13)$.

In a post hoc sensitivity analysis, we removed the three trials that were biased towards no effect ${ }^{14} 1826$ and one trial in which we had prioritised power over contrast in the merging of three intervention groups. ${ }^{16}$ This did not change the results for total mortality (relative risk 0.98 (0.94 to 1.02$)$, cardiovascular mortality (0.97 (0.86 to 1.09$))$, or cancer mortality (1.01 (0.88 to 1.17$)$ ).

\section{Secondary outcomes}

We refer the reader to appendix 2 on bmj.com for detailed results for our secondary outcomes. In summary, we did not find an effect on clinical events, such as coronary heart disease, or other 
measures of morbidity, but they were infrequently reported. One trial found an increased occurrence of hypertension and hypercholesterolaemia with screening. One trial found a $20 \%$ increase in the total number of new diagnoses per participant over six years compared with the control group and an increased occurrence of self reported chronic disease. Other trials reported large numbers of abnormalities detected at the health checks. No trials compared the total number of prescriptions, but two out of four trials found an increased number of people using antihypertensive drugs. Two out of four trials found small beneficial effects on self reported health, but this could be due to reporting bias as the trials were not blinded. We did not find an effect on admission to hospital, disability, worry, additional visits to the physician, or absence from work, but most of these outcomes were poorly studied. We did not find useful results on the number of referrals to specialists, the number of follow-up tests after positive screening results, or the amount of surgery used.

\section{Discussion}

\section{Summary of main results}

We did not find an effect on total or cause-specific mortality from general health checks in adult populations unselected for risk factors or disease. For total mortality, our confidence interval includes a 5\% reduction and a 3\% increase, both of which would be clinically relevant. However, for the causes of death most likely to be influenced by health checks, cardiovascular mortality and cancer mortality, there were no reductions either. A substantial latency of effects on mortality would be expected, but we included several trials with very long follow-up, and they did not show a benefit. Neither did we find a difference in effects in our subgroup analysis comparing trials with up to five years of follow-up with trials with more than five years of follow-up. The results suggest that the lack of effect on total mortality is not a chance finding or due to low power, but that there is no, or only a minimal, effect of the intervention on mortality in general adult populations. We did not include geriatric trials, and our results therefore do not apply to this population.

We also looked at several other outcomes that might be influenced by health checks, but most of these were either infrequently reported or the results were at high risk of bias because of the inevitable lack of blinding and consequent risk of reporting bias and biased loss to follow-up. We did find that health checks led to more diagnoses and more medical treatment for hypertension, as expected, but, as these did not improve mortality or morbidity, they may be considered harms rather than benefits. Two trials found improved self reported health, but the effects were small and could be due to bias.

\section{Strengths and weaknesses of the review}

The main strength of this review is our attempt to reduce bias in the review process by conducting it according to a published and peer reviewed Cochrane protocol and by following empirically founded review guidelines. We identified more relevant trials than previous reviews and did a thorough data collection and appraisal of included studies.

The main limitations are the risk of bias in some of the included trials, their age, and infrequent and poor reporting of some of our specified outcomes, in particular the harms. Another possible limitation is the clinical and methodological heterogeneity among the included trials, although the results were generally consistent for the frequently reported outcomes.

\section{Strengths and weaknesses in relation to other studies}

A systematic review of "the periodic health evaluation" included both trials and observational studies, and also geriatric studies, but it used a different definition of the intervention. ${ }^{6}$ The trials reviewed by us are mostly different ones, but the results are broadly similar with regard to the outcomes that were assessed in both reviews: total mortality, hospitalisation, disability, and the number of new diagnoses (disease detection). In terms of the effects of health checks on participants' health worries, the previous review found one geriatric trial with a beneficial effect, whereas we found two trials with no effect on this outcome. Other reviews studied the effect of calculating and communicating coronary risk, but had a more narrow definition of the intervention, and did not find results on morbidity and mortality. $^{78}$

In order to get the most reliable answers to our questions, we did not include observational studies because the influence of self selection bias is too great compared with the expected small effect of an intervention in a predominantly healthy population. We also chose not to focus on surrogate outcomes such as changes in risk factors or delivery of preventive services, as these may be misleading because an improvement does not necessarily benefit the participant and because they do not measure harms. Nevertheless, we succeeded in identifying several trials that addressed our research questions.

We did not include geriatric trials because they included additional interventions likely to affect the outcomes. A systematic review found that geriatric assessments for general elderly populations reduced the risk of not living at home and of being admitted to a nursing home, but did not find an effect on mortality. ${ }^{28}$

\section{Meaning of the study}

The lack of beneficial effects indicates that the interventions did not work as intended in the included trials. There are several possible explanations for this. Most of the trials were old and consequently used treatments different from what would be used today - such as clofibrate or nicotinic acid for hypercholesterolaemia, instead of statins. Also, thresholds for treating cardiovascular risk factors were higher than they are today. However, it is not a given that the results would be better today, as medical innovations sometimes prove harmful ${ }^{29}$ and as reducing risk factor thresholds means treating people at lower risk who have a smaller potential for benefit but the same risk of harm..$^{30}$ Another possibility is that preventive drugs could have a less favourable balance between benefits and harms when used in general populations compared with in pharmacological trials, which often use many exclusion criteria. ${ }^{31}$ In our meta-analyses, arranged by year of trial start, there are no visible time trends and the idea of increasing benefits over time remains hypothetical. The results on mortality from the Inter99 trial ${ }^{25}$ will be published soon and will inform about the effect of health checks in a modern setting.

Finally, some of the trials used only one health check instead of repeated health checks. For cancer mortality, subgroup analysis showed a trend towards benefit from more than one health check and towards harm from one health check only. For cardiovascular mortality, the opposite trends were observed. We regard these results as chance findings. Also, it is not a given that several health checks would be better than one, as some of the harms would increase.

Two other factors are probably important for explaining our results. First, people who accept an invitation to a health check 
are often different from those who do not. They tend to have higher socioeconomic status, ${ }^{32}$ lower cardiovascular risk, ${ }^{33}$ less cardiovascular morbidity, ${ }^{25}$ and lower mortality. ${ }^{22}$ Thus, systematic health checks may not reach those who need prevention the most, and they have been described as another example of inverse care. ${ }^{33}$ Second, many physicians already carry out testing for cardiovascular risk factors or diseases in patients whom they judge to be at risk when they see them for other reasons. This is often considered an integral part of primary care. Such clinically motivated testing may already have identified many people with disease or elevated risk factors, thus eroding the potential for a benefit from systematic screening.

Our results do not support the use of general health checks aimed at a general adult population outside the context of randomised trials. However, they do not imply that physicians should stop clinically motivated testing and preventive activities, as these may be an important reason why systematic health checks showed no effect. Also, our results do not imply that all individual components of the health checks are ineffective, since effects of harmful components may have balanced out effects of beneficial ones.

\section{Future research}

We suggest that future research is directed at the individual components of health checks, such as screening for cardiovascular risk factors, chronic obstructive pulmonary disease, diabetes, or kidney disease. We also suggest that surrogate outcomes such as changes in risk factors are not used for assessing the benefits of health checks. The large randomised trials with long follow-up that are required are expensive, but not nearly as expensive as the implementation of ineffective or harmful general health check programmes.

We thank Guy De Backer, Walter W Holland, Sven-Olof Isacsson, Torben Jørgensen, Olof Lannerstad, Torsten Lauritzen, David Murray, Charlotta Pisinger, Lennart Welin, and Lars Wilhelmsen for additional information on their trials, and David Mant, Alice Fuller, Holger Theobald, and Janus $L$ Thomsen for providing unpublished outcome data. We also thank the EPOC trials search coordinator, Michelle Fiander, for designing, conducting, and updating the searches, the EPOC Cochrane review group for editorial assistance in producing the corresponding Cochrane review, and the peer reviewers for their valuable comments. This paper is based on a Cochrane review by the same authors. ${ }^{11}$ Cochrane reviews are regularly updated as new evidence emerges and in response to comments and criticisms. The Cochrane Library should be consulted for the most recent version of the review.

Contributors: PCG initiated the project. LTK drafted the protocol, and KJJ and PCG provided comments. LTK, CGL, and KJJ screened titles and abstracts and made decisions about inclusion of trials. LTK and KJJ extracted data. LTK analysed data and drafted the review, and KJJ, $P C G$, and CGL contributed to the revisions. LTK is guarantor.

Funding: LTK was partly supported by a grant from Trygfonden (non-profit foundation). The funder had no role in study design or data collection, analysis, or interpretation.

Competing interests: All authors have completed the ICMJE uniform disclosure form at www.icmje.org/coi_disclosure.pdf (available on request from the corresponding author) and declare: no support from any organisation for the submitted work; no financial relationships with any organisations that might have an interest in the submitted work in the previous three years; no other relationships or activities that could appear to have influenced the submitted work.

Ethical approval: Not required
Data sharing: An excel sheet detailing the inverse variance analyses and the exact numbers used are available from the authors.

Han PKJ. Historical changes in the objectives of the periodic health examination. Ann Intern Med 1997;127:910-7.

2 Holland W. Periodic health examination-a brief history and critical assessment. Eurohealth 2009;15:16-20.

3 Larsen CG, Jørgensen KJ, Gøtzsche PC. Regular health checks: cross-sectional survey. PLoS One 2012;7:e33694.

4 Norris SL, Kansagara D, Bougatsos C, Fu R, for the US Preventive Services Task Force. Screening adults for type 2 diabetes: a review of the evidence for the US Preventive Services Task Force. Ann Intern Med 2008;148:855-68.

5 Sheridan S, Pignone M, Donahue K. Screening for high blood pressure: a review of the evidence for the US Preventive Services Task Force. Am J Prev Med 2003;25:151-8.

6 Boulware LE, Marinopoulos S, Phillips KA, Hwang CW, Maynor K, Merenstein D, et al. Systematic review: the value of the periodic health evaluation. Ann Intern Med 2007;146:289-300.

7 Sheridan SL, Crespo E. Does the routine use of global coronary heart disease risk scores translate into clinical benefits or harms? A systematic review of the literature. BMC Health Serv Res 2008;8:60.

8 Sheridan SL, Viera AJ, Krantz MJ, Ice CL, Steinman LE, Peters KE, et al; Cardiovascular Health Intervention Research and Translation Network Work Group on Global Coronary Heart Disease Risk. The effect of giving global coronary risk information to adults: a systematic review. Arch Intern Med 2010;170:230-9.

9 Fleming TR, DeMets DL. Surrogate end points in clinical trials: are we being misled? Ann Intern Med 1996;125:605-13.

10 Lehman R, Yudkin JS, Krumholz H. Licensing drugs for diabetes. BMJ 2010;341:c4805

11 Krogsbøll LT, Jørgensen KJ, Grønhøj Larsen C, Gøtzsche PC. General health checks in adults for reducing morbidity and mortality from disease. Cochrane Database Syst Rev 2012;(10):CD009009.

12 Shapiro S, Fink R, Rosenberg C. A program to measure the impact of multiphasic health testing on health differentials between poverty and nonpoverty groups. Med Care 1972;10:207-14.

13 Thorner RM, Djordjevic D, Vuckmanovic C, Pesic B, Culafic B, Mark F. A study to evaluate the effectiveness of multiphasic screening in Yugoslavia. Prev Med 1973;2:295-301.

14 The South-East London Screening Study Group. A controlled trial of multiphasic screening in middle-age: results of the South-East London Screening Study. Int J Epidemiol 1977;6:357-63.

15 Bennett AE, Fraser IG. Impact of a screening programme in general practice: a randomized controlled trial. Int J Epidemiol 1972;1:55-60.

16 Imperial Cancer Research Fund OXCHECK Study Group. Effectiveness of health checks conducted by nurses in primary care: final results of the OXCHECK study. BMJ 1995;310:1099-104.

17 Family Heart Study Group. Randomised controlled trial evaluating cardiovascular screening and intervention in general practice: principal results of British family heart study. BMJ 1994;308:313-20.

18 Thomsen JL, Parner ET, Karlsmose B, Thulstrup AM, Lauritzen T, Engberg M. Effect of preventive health screening on long-term primary health care utilization. A randomized controlled trial. Fam Pract 2005;22:242-8.

19 Tibblin G, Welin L, Larsson B, Ljungberg IL, Svärdsudd K. The influence of repeated health examinations on mortality in a prospective cohort study, with a comment on the autopsy frequency. The study of men born in 1913. Scand J Soc Med 1982;10:27-32.

20 Lannerstad O, Sternby NH, Isacsson SO, Lindgren G, Lindell SE. Effects of a health screening on mortality and causes of death in middle-aged men. A prospective study from 1970 to 1974 of men in Malmö, born 1914. Scand J Soc Med 1977;5:137-40.

21 Theobald H, Bygren LO, Carstensen J, Hauffman M, Engfeldt P. Effects of an assessment of needs for medical and social services on long-term mortality: a randomized controlled study. Int J Epidemiol 1998;27:194-8.

22 Wilhelmsen L, Berglund G, Elmfeldt D, Tibblin G, Wedel H, Pennert K, et al. The multifactor primary prevention trial in Göteborg, Sweden. Eur Heart $J 1986 ; 7: 279-88$.

23 Olsen D, Kane R, Proctor P. A controlled trial of multiphasic screening. N Engl J Med 1976;294:925-30.

24 Murray DM, Luepker RV, Pirie PL, Grimm RH Jr, Bloom E, Davis MA, et al. Systematic risk factor screening and education: a community-wide approach to prevention of coronary heart disease. Prev Med 1986;15:661-72.

25 Jørgensen T, Borch-Johnsen K, Thomsen TF, Ibsen H, Glümer C, Pisinger C. A randomized non-pharmacological intervention study for prevention of ischaemic heart disease: baseline results Inter99. Eur J Cardiovasc Prev Rehabil 2003;10:377-86.

26 Friedman GD, Collen MF, Fireman BH. Multiphasic health checkup evaluation: a 16-year follow-up. J Chron Dis 1986;39:453-63.

27 World Health Organization European Collaborative Group. WHO European collaborative trial in the multifactorial prevention of coronary heart disease. WHO, 1989.

28 Beswick AD, Rees K, Dieppe P, Ayis S, Gooberman-Hill R, Horwood J, et al. Complex interventions to improve physical function and maintain independent living in elderly people: a systematic review and meta-analysis. Lancet 2008;371:725-35.

29 Prasad V, Gall V, Cifu A. The frequency of medical reversal. Arch Intern Med 2011;171:1675-6.

30 Welch HG, Schwartz L, Woloshin S. Overdiagnosed-making people sick in the pursuit of health. Beacon Press, 2011.

31 Uijen AA, Bakx JC, Mokkink HGA, van Weel C. Hypertension patients participating in trials differ in many aspects from patients treated in general practices. J Clin Epidemiol 2007;60:330-5.

32 Pill R, French J, Harding K, Stott N. Invitation to attend a health check in a general practice setting: comparison of attenders and non-attenders. J R Coll Gen Pract 1988;38:53-6.

33 Waller D, Agass M, Mant D, Coulter A, Fuller A, Jones L. Health checks in general practice: another example of inverse care? BMJ 1990;300:1115-8.

Accepted: 15 October 2012

\section{Cite this as: BMJ 2012;345:e7191}

This is an open-access article distributed under the terms of the Creative Commons Attribution Non-commercial License, which permits use, distribution, and reproduction in 


\section{What is already known on this subject}

General health checks are widely assumed to be effective in reducing morbidity and mortality from disease based on common sense and on observations of reductions in risk factors and increased delivery of preventive services

However, a demonstration of benefits in terms of morbidity and mortality has been lacking

\section{What this study adds}

This systematic review of randomised trials suggest that general health checks in adults may not reduce morbidity or mortality from disease

Harms were sparsely studied in individual trials. Since health checks probably increase the number of diagnoses, the absence of benefits suggests overdiagnosis and overtreatment

Current use of general health checks is not supported by the best available evidence 


\section{Tables}

\begin{tabular}{|c|c|c|c|c|c|c|c|c|c|}
\hline \multirow{2}{*}{$\begin{array}{l}\text { Trial name or } \\
\text { location, and year of } \\
\text { trial start }\end{array}$} & \multirow{2}{*}{$\begin{array}{c}\text { Group size } \\
\text { (intervention/ } \\
\text { control)* }\end{array}$} & \multirow[b]{2}{*}{$\begin{array}{l}\text { Follow-up } \\
\text { (years) }\end{array}$} & \multirow[b]{2}{*}{$\begin{array}{l}\text { Sex, age range } \\
\quad \text { (years) }\end{array}$} & \multirow[b]{2}{*}{$\begin{array}{l}\text { Recruited } \\
\text { from }\end{array}$} & \multicolumn{4}{|c|}{ Health checks } & \multirow{2}{*}{$\begin{array}{l}\text { Included } \\
\text { in } \\
\text { mortality } \\
\text { analyses }\end{array}$} \\
\hline & & & & & Performed at & $\begin{array}{c}\text { Lifestyle } \\
\text { intervention }\end{array}$ & $\begin{array}{l}\text { No of } \\
\text { checks }\end{array}$ & $\begin{array}{l}\text { Uptake } \\
\text { (\%)† }\end{array}$ & \\
\hline $\begin{array}{l}\text { Göteborg, Sweden } \\
1963^{19}\end{array}$ & $1010 / 1956$ & 15 & Men, 50 & Community & Hospital & No & 3 & 85 & Yes \\
\hline $\begin{array}{l}\text { Kaiser Permanente, } \\
\text { USA } 1965^{26}\end{array}$ & $5138 / 5536$ & 16 & $\begin{array}{c}\text { Men and women, } \\
35-54\end{array}$ & $\begin{array}{l}\text { Health plan } \\
\text { members }\end{array}$ & Screening clinic & No & N/A & N/A & Yes \\
\hline $\begin{array}{l}\text { South east London, UK } \\
1967^{14}\end{array}$ & $3292 / 3132$ & 9 & $\begin{array}{c}\text { Men and women, } \\
40-64\end{array}$ & GP lists & Screening clinic & No & 2 & 73 & Yes \\
\hline $\begin{array}{l}\text { Northumberland, UK } \\
1969^{15}\end{array}$ & $242 / 291$ & $11 / 2$ & Men, 50-59 & GP lists & GP & No & 1 & 90 & No \\
\hline Malmö, Sweden $1969^{20}$ & $809 / 804$ & 5 & Men, 55 & Community & $\begin{array}{c}\text { Unclear, but not } \\
\text { GP }\end{array}$ & No & 1 & 87 & Yes \\
\hline $\begin{array}{l}\text { Stockholm, Sweden } \\
1969^{21}\end{array}$ & $3064 / 29122$ & 22 & $\begin{array}{c}\text { Men and women, } \\
18-65\end{array}$ & Community & $\begin{array}{c}\text { Unclear, but not } \\
\text { GP }\end{array}$ & No & 1 & 84 & Yes \\
\hline $\begin{array}{l}\text { Göteborg, Sweden } \\
1970^{22}\end{array}$ & 10 004/20 018 & 11.8 & Men, 47-55 & Community & $\begin{array}{c}\text { Unclear, but not } \\
\text { GP }\end{array}$ & Yes & 2 & 75 & Yes \\
\hline WHO, Europe $1971^{27}$ & 30 489/26 971 & 5 to 6 & Men, 40-59 & Workplace & Workplace & Yes & 1 & 86 & Yes \\
\hline $\begin{array}{l}\text { Salt Lake City, USA } \\
1972^{23}\end{array}$ & $642 / 454$ & 1 & $\begin{array}{c}\text { Men and women, } \\
\geq 18\end{array}$ & Community & Screening clinic & No & 1 & 60 & No \\
\hline Mankato, USA $1982^{24}$ & $1156 / 1167$ & 1 & $\begin{array}{c}\text { Men and women, } \\
25-74\end{array}$ & Community & Screening clinic & Yes & 1 & 50 & No \\
\hline OXCHECK, UK $1989^{16}$ & $8307 / 2783$ & 4 & $\begin{array}{c}\text { Men and women, } \\
\text { 35-64 }\end{array}$ & GP lists & GP & Yes & $1-3$ & $\sim 80$ & Yes \\
\hline $\begin{array}{l}\text { Family heart, UK } \\
1990^{17}\end{array}$ & $3436 / 9488$ & 1 & $\begin{array}{c}\text { Men and women, } \\
40-59\end{array}$ & GP lists & GP & Yes & 1 & 73 & No \\
\hline $\begin{array}{l}\text { Ebeltoft, Denmark } \\
1992^{18}\end{array}$ & $2030 / 1434$ & 8 & $\begin{array}{c}\text { Men and women, } \\
\text { 30-49 }\end{array}$ & GP lists & GP & Yes & 2 & 90 & Yes \\
\hline $\begin{array}{l}\text { Inter99, Denmark } \\
1999^{25}\end{array}$ & $6784 / 3321 \S$ & $5 \S$ & $\begin{array}{c}\text { Men and women, } \\
30-60\end{array}$ & Community & Screening clinic & Yes & $2-4$ & 53 & No \\
\hline
\end{tabular}

$\mathrm{GP}=$ general practice.

*Groups merged in some trials.

†Uptake at first round.

$\ddagger$ This trial did not have screening rounds but continuous urging of the intervention group by written invitations and telephone calls to use a prepaid health check. $\S$ Sample size of follow-up length for the analysis of self reported health. The trial was larger, with 13016 participants randomised to health checks and 48285 to control, followed for 10 years, but full results not yet published. 


\section{Table 2| Summary of methods of studies included in analysis}

Trial name or location, and year of trial start

Göteborg, Sweden $1963^{19}$

\section{Methods}

Included all men born in 1913 and living in Göteborg, Sweden, in 1962. Allocation of participants was done according to date of birth before any contact was made. The intervention group was invited for 3 rounds of health checks, and the control group was not contacted. All were followed through registries for mortality.

Kaiser Permanente, USA $1965^{26}$ In April 1964, a sample of eligible members of the Kaiser-Permanente Health Plan in San Francisco and Oakland was divided into an intervention group and a control group using an allocation rule based on membership number. Starting in 1965, people in the intervention group were urged annually, by telephone and letter, to have the multiphasic screening examination offered by the Kaiser Health Plan. The intervention was continued for 16 years. Participants were followed using mailed questionnaires, patient records, and registers.

South east London, UK $1967^{14}$ Eligible people were identified through GP registers and randomised by family to intervention or control by alternate allocation of alphabetically ordered names. The intervention group was invited by letter to two rounds of health checks, with a two year interval. After five years, both groups were invited for health checks and measurement of some outcomes. A later publication state that this screening was not expected to result in therapeutic activity. Follow-up was continued for a further four years through records and registers.

Northumberland, UK $1969^{15} \quad$ All eligible men were allocated at the same time before any contact was made, excluding $7 \%$ because of serious illness. Participants were allocated by date of birth to one of three groups: questionnaire and full examination, questionnaire and examination if indicated by answers to the questionnaire, and neither questionnaire nor examination. We used the first and the last group in our analyses. Outcomes were assessed from medical records.

Malmö, Sweden $1969^{20} \quad$ Included all men born in 1914 and living in Malmö, Sweden, in early 1969. Men born in even-numbered months were invited to screening, and men born in uneven-numbered months were not. Outcomes were ascertained through registers.

Stockholm, Sweden $1969^{21} \quad$ A double sample was drawn from the eligible population and divided into three age groups. From these, a random sample was drawn using sample fractions in the proportions of 3:2:1, with the highest fraction for the youngest age stratum. These were sent a questionnaire about social and physical difficulties and health needs. Based on this, and on data from the public inpatient register, they were substratified by expected needs for medical services (high, low, none, and unknown need). Randomisation to screening and control groups took place within these strata, but proportionally more were randomised to screening in the high and low need groups than in the no or unknown need groups. The authors used regression analysis to control for baseline imbalances introduced by the randomisation scheme and age and sex. We obtained data from the authors and conducted a fixed effects meta-analysis of the effects obtained in each stratum, and found nearly identical results to those of authors. Results from this analysis were used in the meta-analysis. Participants were followed for mortality in registers.

Göteborg, Sweden $1970^{22} \quad$ Included men in Göteborg who were born in 1915-22 and in 1924-25. These were randomised to an intervention group and two control groups. They were followed in registers for mortality and morbidity.

WHO, Europe $1971^{27} \quad$ Forty matched pairs of factories in four European countries (UK, Belgium, Poland, and Italy) were randomised to intervention or control. Follow-up varied between factories, but was between 5 and 6 years. Cancer mortality was not ascertained in the Belgian part of the trial.

Salt Lake City, USA $1972^{23} \quad$ Included random samples of low and middle income families, both with and without prepaid healthcare. Randomised by family. Allocation ratio was 3:2 (intervention:control). Intervention group was urged by telephone to have a free health check. Outcomes were ascertained at interview after one year.

Mankato, USA $1982^{24} \quad$ Addresses representing the entire community were randomised. In the intervention group, the whole household was invited for screening, but only one eligible participant from each household, selected randomly, was included in the trial and followed. The control group was not invited. After one year, participants in the intervention group who attended the initial screening were re-invited, and the control group was invited for their first time.

OXCHECK, UK $1989^{16} \quad$ Eligible people who returned an initial questionnaire were included and randomised by household into four groups: health checks at year 1 and 4; at year 2 and 4; at year 3 and 4; and only at year 4. Participants in the first two groups were further randomised to annual re-checks or no re-checks. We regarded the first three groups as the intervention group and the last group as the control group. We obtained data on mortality and cancer incidence from the authors.

Family heart, UK $1990^{17} \quad$ Thirteen matched pairs of general practices were randomised to intervention or control (external control group). In the intervention practices, eligible men were randomised to either intervention or control (internal control group), and their partners were included. The intervention group was invited for health check and lifestyle intervention at baseline. After one year both intervention and control groups were invited. Only those participants who attended their first health check were included in the analyses (that is, at baseline for intervention group and after one year for control group).

Ebeltoft, Denmark $1992^{18} \quad$ A random sample of 2000 was taken from the eligible population of 3464 . The sample was sent a short questionnaire, and participants returning the questionnaire and giving consent $(n=1507)$ were included and randomised into three groups: offered health checks ( $n=502)$, offered health checks plus health discussions $(n=504)$, and usual care $(n=501)$. Participants were followed in registers for eight years, and comparisons were made between (a) the three intervention groups and $(b)$ the 2000 randomly invited to participate in the trial (plus 30 in whom invitation failed for administrative reasons) and the 1434 not invited. We preferentially used the results from the second comparison.

Inter99, Denmark $1999^{25} \quad$ All 61301 people aged 30, 35, 40, 45, 50, 55, and 60 years and living in 11 municipalities in the south western part of Copenhagen County on 2 December 1998 were included. A random sample was invited to screening, and the rest constituted the control group. The intervention group and a random subsample of the control group had questionnaires at baseline and after 1,3 , and 5 years of follow-up. All participants were followed up through central registers. Results on morbidity and mortality are not yet published. 


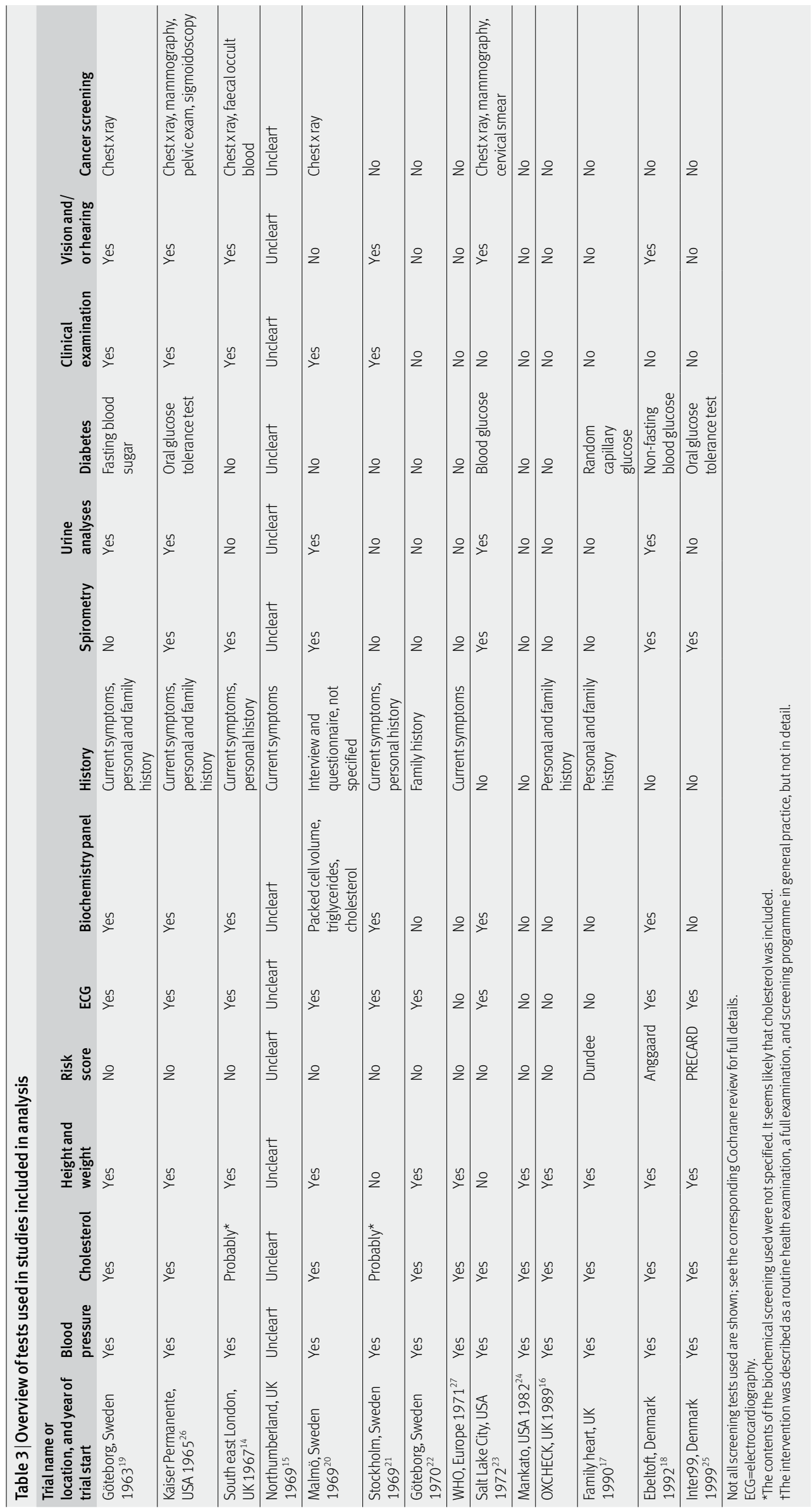




\section{Figures}

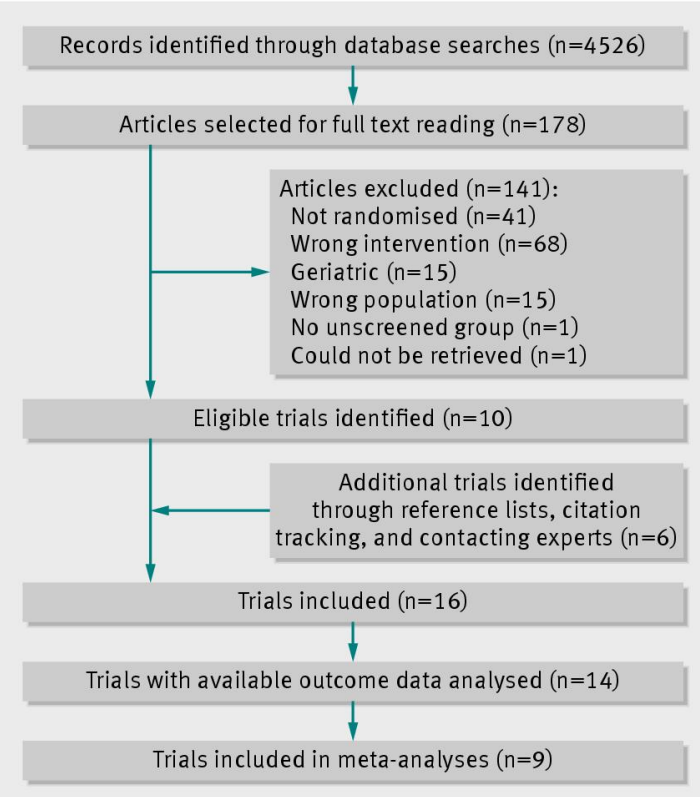

Fig 1 Details of literature search and study selection 


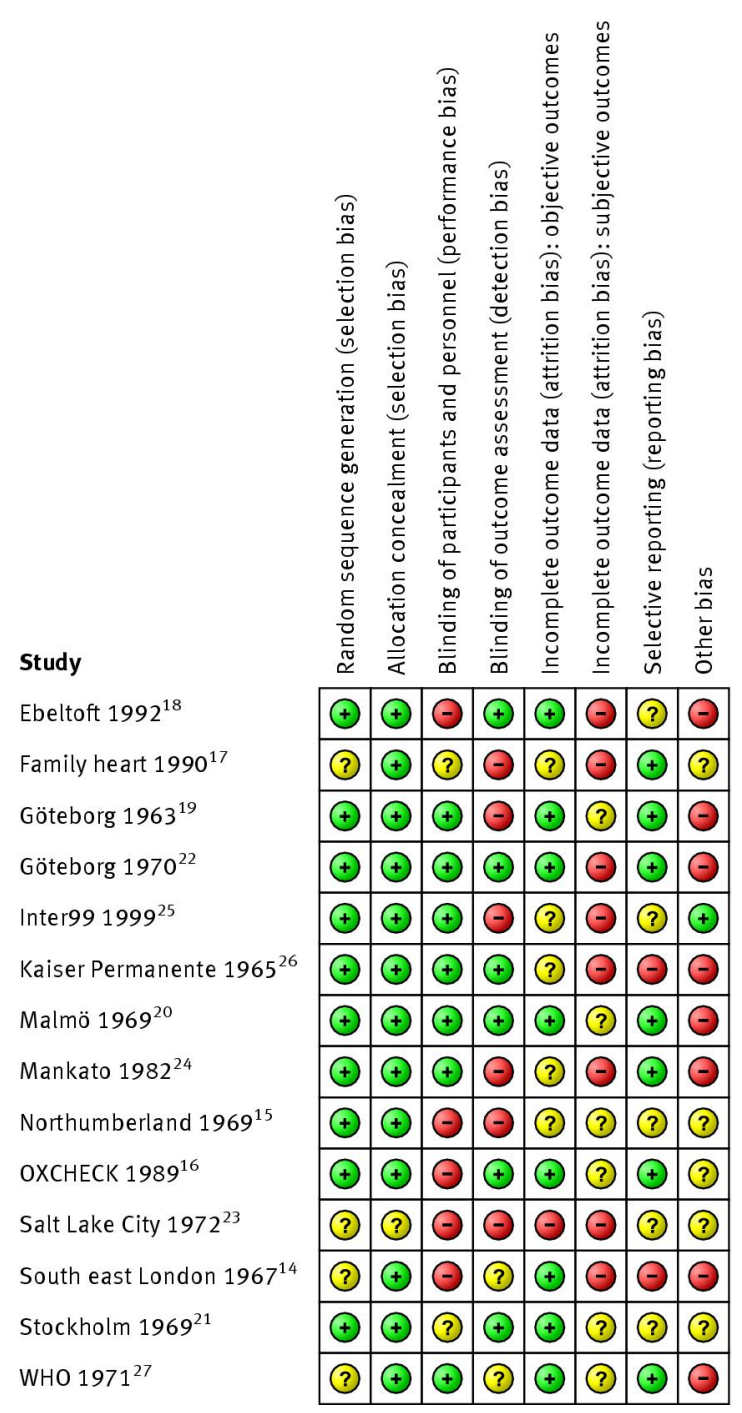

Fig 2 Summary of risk of bias in studies included in the analysis. Some cells contain assessments on multiple outcomes. (See corresponding Cochrane review for full details ${ }^{11}$ )

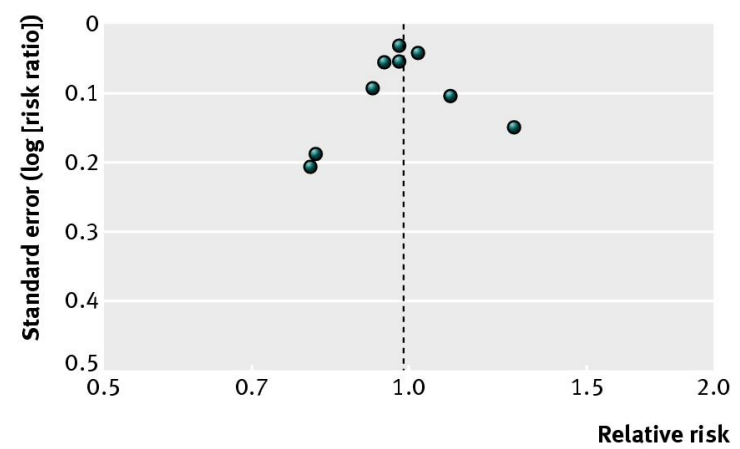

Fig 3 Funnel plot for studies of effects of general health checks on total mortality 


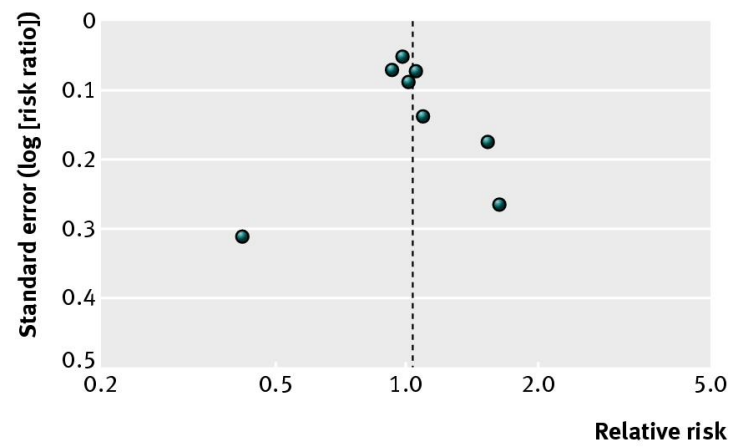

Fig 4 Funnel plot for studies of effects of general health checks on cardiovascular mortality

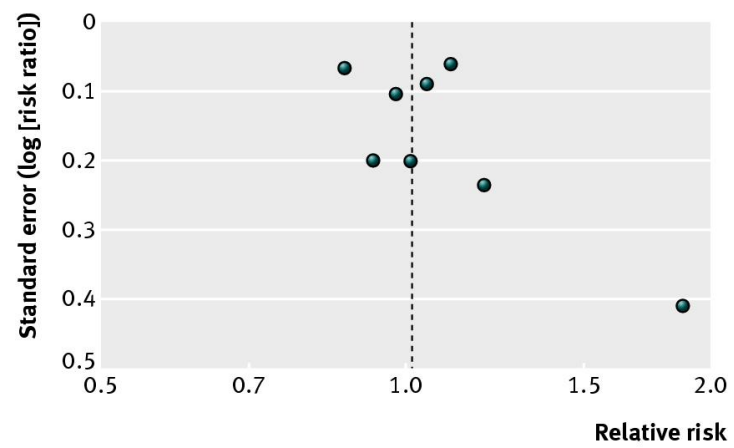

Fig 5 Funnel plot for studies of effects of general health checks on cancer mortality

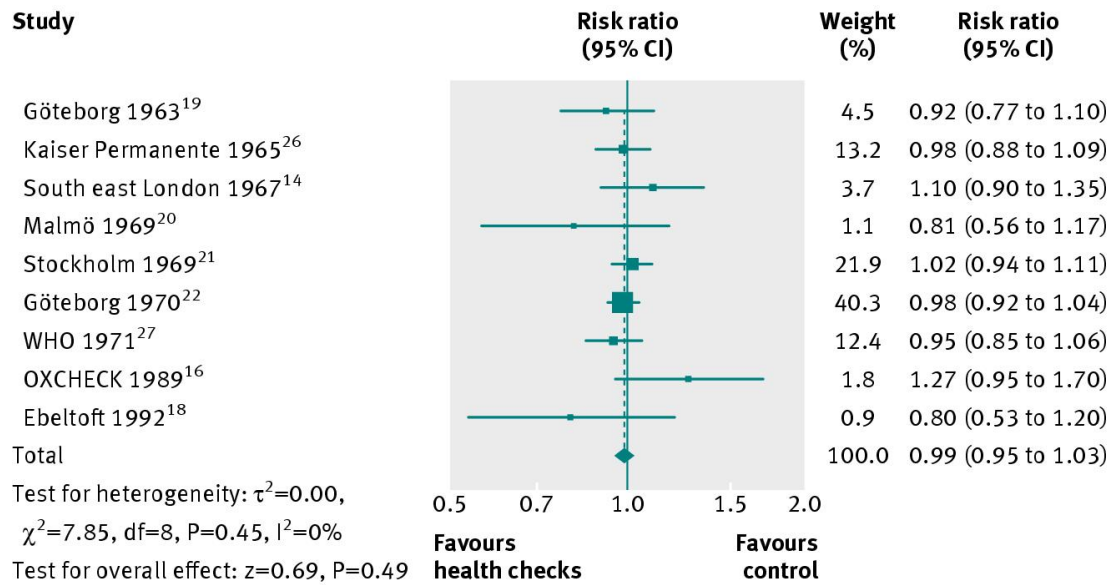

Fig 6 Forest plot showing effect of general health checks on total mortality. Year indicates the year of trial start 
Study

\section{Göteborg $1963^{19}$}

Kaiser Permanente $1965^{26}$

South east London $1967^{14}$

Malmö $1969^{20}$

Stockholm $1969^{21}$

Göteborg $1970^{22}$

WHO $1971^{27}$

OXCHECK $1989^{16}$

Total

Test for heterogeneity: $\tau^{2}=0.02$,

$\chi^{2}=19.32, \mathrm{df}=7, \mathrm{P}=0.007, \mathrm{I}^{2}=64 \%$

Test for overall effect: $z=0.50, P=0.62$ health checks

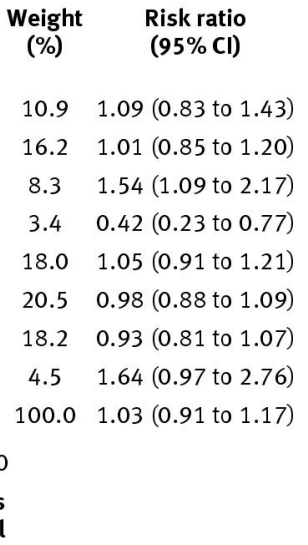

control

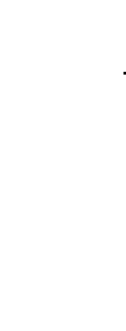

